\title{
QUALIDADE DA ÁGUA DE UMA MICROBACIA COM FINS DE ABASTECIMENTO PÚBLICO, CHAPADA DOS GUIMARÃES, MT
}

\author{
P. A. J. GOMES-SILVA, S. D. LIMA, R. GOLIN, D. M. FIGUEIREDO, Z. M. LIMA, E. B. MORAIS e E. F. G. C. DORES \\ Universidade Federal de Mato Grosso - UFMT \\ gestorambiental.paulo@gmail.com
}

Artigo submetido em fevereiro/2014 e aceito em agosto/2014

DOI: 10.15628/holos.2014.1977

\section{RESUMO}

A urbanização de forma desordenada tem se elevado nas bacias hidrográficas, podendo levar ao desequilíbrio ambiental e, por conseguinte, riscos à saúde humana. Um exemplo desse desequilíbrio é a deterioração da qualidade da água dos corpos d'água. Sabe-se que uma água de qualidade é fundamental à vida humana. Neste sentido, esta pesquisa teve como objetivo medir as condições limnológicas e de qualidade da água da microbacia do córrego do Quineira, a fim de avaliar a atual situação deste importante recurso natural, que é utilizado para o abastecimento público do município de Chapada dos Guimarães, Mato Grosso e propor medidas mitigadoras com vistas à proteção ambiental de modo geral, bem como gerar dados que subsidiarão a gestão dos recursos hídricos dessa cidade

PALAVRAS-CHAVE: Limnologia, Qualidade da água, Microbacia, Chapada dos Guimarães-MT.

\section{WATER QUALITY OF A WATERSHED USED FOR PUBLIC SUPPLY, CHAPADA DOS GUIMARÃES, MT}

\begin{abstract}
Urbanization in a disorderly manner has increased in watersheds and may lead to environmental imbalance and therefore risks to human health. An example of this imbalance is the deterioration of water quality of water bodies. It is known that a water quality is vital to human life. In this sense, this research aimed to measure the limnological conditions and water quality of the
\end{abstract}

watershed of the Quineira creek in order to assess the current status of this important natural resource, which is used for public supply in the municipality of Chapada dos Guimarães, Mato Grosso and to propose mitigating measures aimed at environmental protection in general, as well as to generate data that will subsidize the management of water resources of this city.

KEYWORDS: Limnology, Water Quality, Watershed, Chapada dos Guimarães-MT. 


\section{INTRODUÇÃO}

A água é um elemento essencial para a humanidade e demais formas de vida do planeta Terra. Contudo, este recurso natural extremamente importante para a manutenção da vida tem sido utilizado muitas vezes de forma inadequada. Além disso, sua utilização é presente em todas as formas de produção, que com o decorrer dos tempos tem sido explorada de forma mais intensa, devido ao crescimento populacional-econômico, o que demanda maior produção de bens de consumo e serviços, para suprir as necessidades individuais de cada ser humano.

O termo água refere-se, em regra geral, ao elemento natural, desvinculado de qualquer uso ou utilização. Por sua vez, o termo recurso hídrico é a consideração da água como bem econômico, possível de utilização com tal fim. Entretanto, deve-se ressaltar que toda água da Terra não é, necessariamente, um recurso hídrico, na medida em que seu uso ou utilização nem sempre tem viabilidade econômica (REBOUÇAS, 2006).

A urbanização desordenada das bacias hidrográficas pode gerar diversos desequilíbrios ao meio ambiente e, consequentemente, danos ao homem. Uma das consequências provocadas pela falta de planejamento da ocupação e uso do solo é a alteração de alguns processos inerentes ao ciclo hidrológico e, por conseguinte na disponibilidade hídrica com quantidade e na qualidade da água necessária para utilização. As principais causas desses processos estão relacionadas com a limitada gestão do uso do solo, da infraestrutura de água, práticas inadequadas de sustentabilidade urbana e baixo investimento (TUCCI, 2008).

Segundo Von Sperling (1996), a qualidade da água resulta de fenômenos naturais e das interferências do homem. Assim, pode-se afirmar que a qualidade da água de uma determinada região está relacionada com as condições naturais e também ao uso e ocupação do solo de uma bacia hidrográfica (BH).

Para avaliar a qualidade das águas superficiais, os padrões utilizados para a comparação dos resultados constam na Resolução do Conselho Nacional do Meio Ambiente (CONAMA) no $357 / 2005$ que trata da classificação dos corpos d'água e diretrizes ambientais para o seu enquadramento, baseado no uso predominante atual e pretendido, sendo divididas em cinco classes (Especial, 1, 2, 3 e 4) de acordo com sua qualidade. No Estado de Mato Grosso, todos os rios são considerados de classe 2 , pois ainda não existe enquadramento oficial. Para avaliar a balneabilidade, os resultados para Escherichia coli serão comparados com a resolução n 274/2000 do CONAMA.

Atualmente, pelo fato de estudar alterações provocadas pelas diferentes atividades humanas nos ecossistemas aquáticos, a limnologia é uma importante ferramenta na gestão dos recursos hídricos, principalmente na análise de impactos ambientais de empreendimentos que fazem algum tipo de uso da água (FIGUEIREDO, 2009).

Consideram-se impactos ambientais de acordo com a Resolução CONAMA no 001/1986 em seu artigo 1으, qualquer alteração das propriedades físicas, químicas e biológicas do meio ambiente, causada por qualquer forma de matéria ou energia resultante das atividades humanas que, direta ou indiretamente, afetam: (1) a saúde, a segurança e o bem-estar da população; (2) as atividades sociais e econômicas; (3) a biota; (4) as condições estéticas e sanitárias do meio ambiente; (5) a qualidade dos recursos ambientais. 
Nesse contexto, o objetivo deste trabalho foi de avaliar as condições limnológicas e a qualidade da água da microbacia do córrego, Quineira que drena a área urbano-central do município de Chapada dos Guimarães, Mato Grosso, sendo um importante corpo d'água utilizado para abastecimento público, comparando os resultados com os padrões legais, a fim de verificar os possíveis impactos oriundos de atividades antrópicas ali existentes e gerar dados que possam subsidiar a gestão dos recursos hídricos e o planejamento do uso e ocupação do solo no entorno da microbacia objeto desta pesquisa, para que haja medidas preventivas e corretivas para o equilíbrio ambiental da área estudada.

\section{MATERIAL E MÉTODOS}

O município de Chapada dos Guimarães localiza-se na região central da América do Sul, no Estado de Mato Grosso a cerca de $60 \mathrm{~km}$ da capital Cuiabá, mais precisamente entre as coordenadas geográficas 15 10' - 15 30' latitude Sul e 55 40' -56 00' longitude Oeste. O córrego do Quineira, corpo d'água objeto deste estudo, está inserido dentro do Parque Estadual do Quineira e drena parte da área urbana do município, tendo o comprimento do rio principal 2.688 $\mathrm{m}$, área de 3,43 $\mathrm{km}^{2}$ e Coeficiente de Compacidade $(\mathrm{Kc})$ de 1,25 indicando que a microbacia possui forma alongada, menos propensa às enchentes, Figura 1.

A microbacia do Quineira encontra-se dentro da sub-bacia do rio Cachoeirinha, que compõe a Bacia do rio Cuiabá, que por sua vez compõe a Bacia do Alto Paraguai. A área está localizada na Bacia Sedimentar do Paraná, geomorfologicamente na região do Planalto dos Guimarães. A cidade de Chapada dos Guimarães encontra-se, em grande parte, sobre Latossolo, que é um solo permeável e que pode ser encontrado, inclusive nas porções mais planas das encostas. Segundo Salomão et al. (2012), esta microbacia possui o solo constituído de Latossolo Vermelho e Latossolo Vermelho Amarelo, de textura argilosa, e também por Plintossolo Pétrico, sendo associados a rochas pertencentes à Formação Ponta Grossa e transição Furnas-Ponta Grossa, sendo constituídas por argilitos e arenitos.

Para a análise de água devem ser considerados valores de parâmetros de acordo com a legislação vigente. Sendo assim, foi utilizada a resolução do Conselho Nacional do Meio Ambiente (CONAMA) no 357/05 que classifica os corpos d'água de acordo com seu uso e qualidade, dividindo as águas em cinco classes. Tendo em vista os rios de Mato Grosso não possuírem enquadramento oficial dos seus cursos de água, a legislação determina que estes sejam avaliados como de classe 2. Para a análise das águas naturais (nascentes), a resolução utilizada foi a de Diretoria Colegiada da Agência Nacional de Vigilância Sanitária (ANVISA) no 275/05.

A amostragem foi realizada no dia 15 de maio de 2013, seguindo os pontos já préestabelecidos no planejamento. Foram analisados os parâmetros físicos, químicos e microbiológicos da água do córrego Quineira, ao longo do gradiente longitudinal da microbacia, compreendendo a região de cabeceira, partes média e alta da microbacia conforme a Figura 1, sendo denominados de P1 (Complexo de Nascentes), P2 (Confluência de Nascentes), P3 (Captação SAAE), P4 (Piscina Pública), P5 (Jusante lançamento de esgoto sanitário) e P6 (Exutório). A coleta e preservação das amostras foram realizadas de acordo com CETESB (2011). Já os métodos de análise das amostras seguiram o que determina APHA (2012). 


\section{Pontos Coleta de Água}

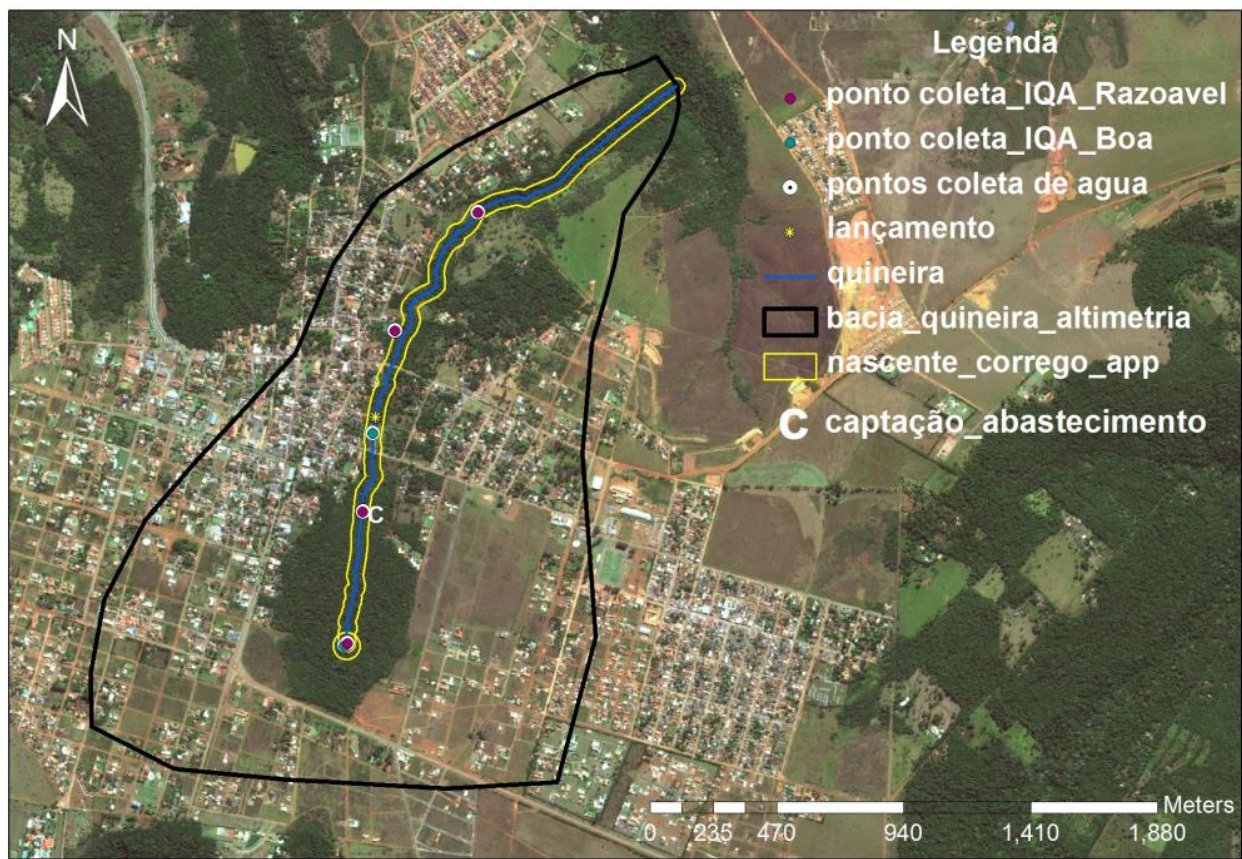

Figura 1 - Mapa de delimitação e localização e pontos amostrais.

Fonte - Froés Filho, 2013.

Foram feitas seis amostragens no período de estiagem, e os parâmetros analisados estão descritos nas Tabelas 1 e 2 e as características morfométricas encontram-se na Tabela 3.

Tabela 1 - Parâmetros e Técnicas Analíticas Utilizadas. Cuiabá, junho/2013.

\begin{tabular}{|c|c|c|}
\hline PARÂMETROS & TÉCNICA ANALÍTICA & UNIDADE \\
\hline $\mathrm{pH}$ & Direto, Potenciométrico & ------------- \\
\hline OD & Standard Methods, Multisonda & $\mathrm{mg} \cdot \mathrm{L}^{-1}$ \\
\hline DBO & Standard Methods, 5 dias a $20^{\circ} \mathrm{C}$ & $\mathrm{mg} \cdot \mathrm{L}^{-1}$ \\
\hline Condutividade elétrica & Direto, Multisonda & $\mu \mathrm{S} . \mathrm{cm}^{-1}$ \\
\hline Turbidez & Turbidímetro & UNT \\
\hline
\end{tabular}

Fonte - Laboratório Físico-Químico DESA/UFMT.

Tabela 2 - Parâmetros e Técnicas Analíticas Utilizadas. Cuiabá, junho/2013.

\begin{tabular}{c|c|c}
\hline PARÂMETROS & TÉCNICA ANALÍTICA & UNIDADE \\
\hline $\begin{array}{c}\text { Coliformes totais } \\
\text { Eschirichia coli }\end{array}$ & Substrato enzimático cromogênico/fluorogênico Colilert & \\
\hline
\end{tabular}

Fonte - Laboratório de microbiologia DESA/UFMT. 
Tabela 3 - Características morfométricas.

\begin{tabular}{c|c}
\hline CARACTERÍSTICAS MORFOMÉTRICAS & DIMENSÕES \\
\hline Perímetro & $8,24 \mathrm{~km}$ \\
\hline Comprimento do canal principal & $2.668 \mathrm{~m}$ \\
\hline Área da bacia & $3,43 \mathrm{~km}^{2}$ \\
\hline Largura média & $1,11 \mathrm{~km}$ \\
\hline Ordem do rio & $0,87 \mathrm{~km} / \mathrm{km}^{2}$ \\
\hline Densidade de drenagem & $30,93 \mathrm{~min}$. \\
\hline Tempo de concentração & 0,36 \\
\hline Fator de forma & 1,25
\end{tabular}

Fonte - Os autores, 2013.

\section{RESULTADOS E DISCUSSÃO}

\subsection{Oxigênio Dissolvido e Demanda Bioquímica de Oxigênio}

O oxigênio dissolvido (OD) é um dos gases mais importantes na dinâmica e na caracterização de ecossistemas aquáticos, tendo como principais fontes a atmosfera e fotossíntese de acordo com Esteves (2011). Geralmente, o oxigênio se reduz ou desaparece quando a água recebe grandes quantidades de substâncias orgânicas, biodegradáveis. A quantidade de oxigênio na água depende da temperatura e da altitude (pressão atmosférica do local), pois a solubilidade deste gás depende destes fatores (LIMA, 1998). Assim, este parâmetro é essencial para os organismos aeróbicos que o utiliza tanto para os processos de decomposição de matéria orgânica, como para a própria respiração segundo Von Sperling (1996), sendo um fator limitante para a biota aquática.

\section{OD x DBO}

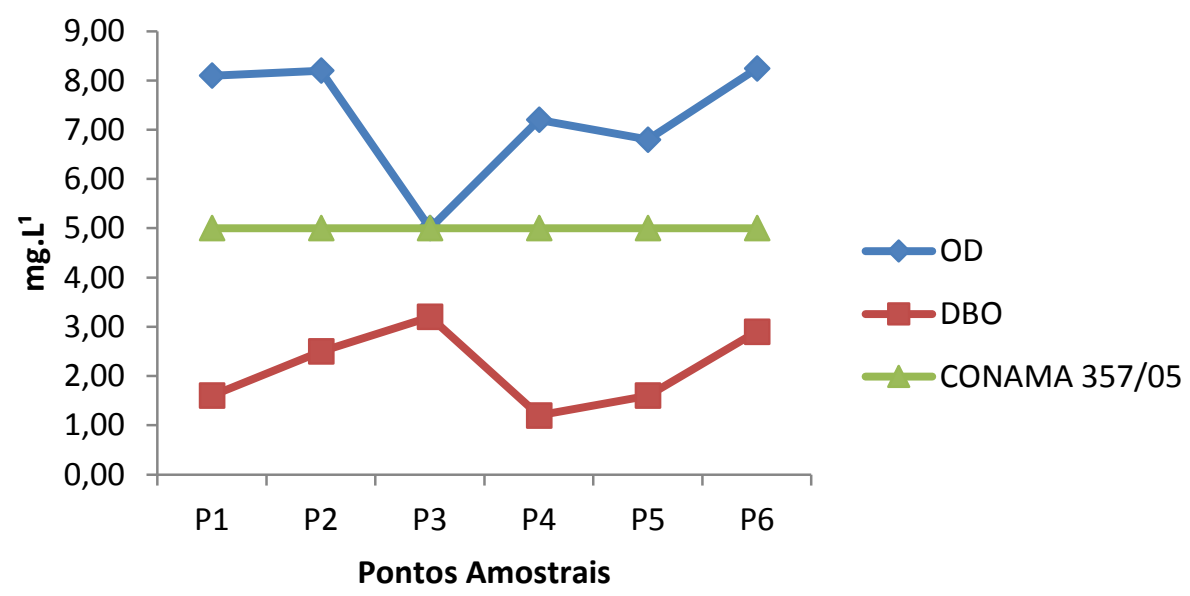

Figura 2 - Variação da concentração de oxigênio dissolvido e demanda bioquímica de oxigênio ao longo do Córrego Quineira, Chapada do Guimarães, MT

Os resultados nos remetem a condições equilibradas para oxigênio dissolvido (OD) e relativamente para a demanda bioquímica de oxigênio (DBO), estando todos os pontos amostrais 
dentro dos padrões da resolução do CONAMA 357/05 (Figura 2). Há uma maior redução de OD bem como aumento de DBO no P3, tendo este resultado ligação com a característica do ponto amostral, onde existe um barramento para captação de água pela empresa de abastecimento público do município, aumentando as concentrações de diversas matérias orgânicas e inorgânicas bem como a estagnação da vazão. Já a elevação de DBO para P6 está relacionado provavelmente ao lançamento de esgoto sanitário in natura a montante, que foi verificado in loco nas proximidades de $\mathrm{P} 4$ e residência às margens de $\mathrm{P} 5$.

\subsection{Potencial Hidrogeniônico $(\mathrm{pH})$}

O potencial hidrogeniônico $(\mathrm{pH})$ segundo Esteves (2011) interfere de diferentes formas no metabolismo de um ecossistema aquático. Sobre as comunidades, o $\mathrm{pH}$ atua diretamente nos processos de permeabilidade da membrana celular, interferindo também no transporte iônico intra e extracelular e entre os organismos do meio.

A legislação do CONAMA no 357/05 determina que o valor do pH esteja entre os valores de 6 e 9.

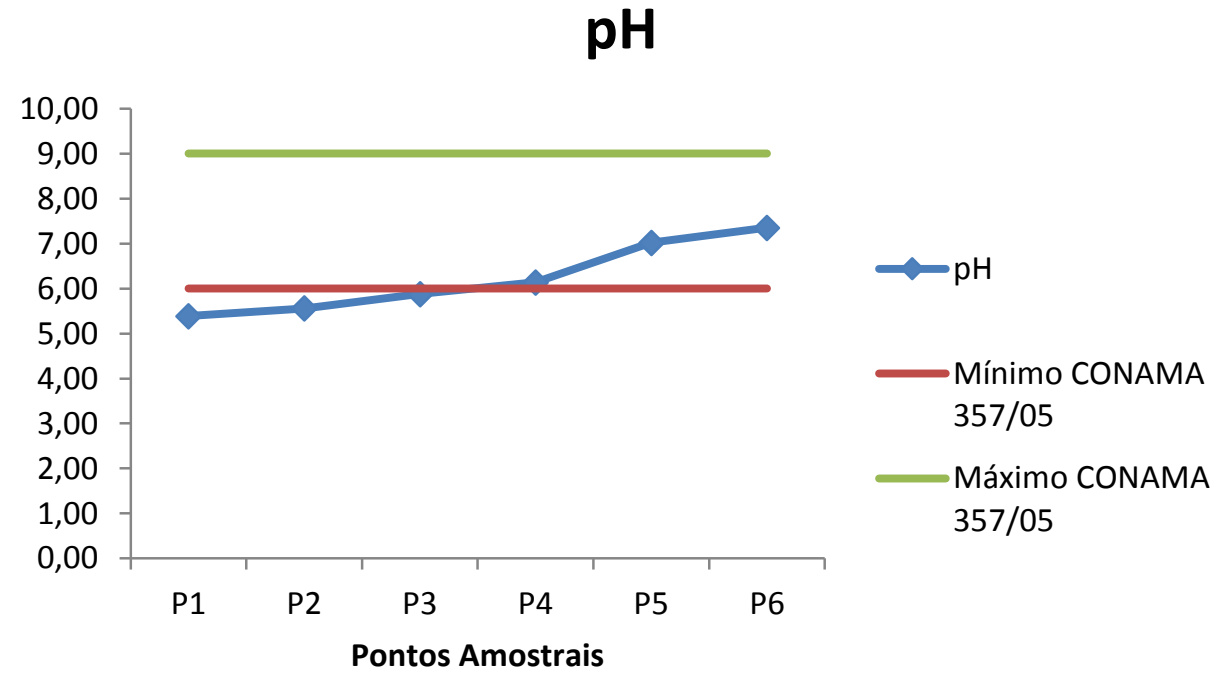

Figura 3 - Variação do pH da água ao longo do Córrego Quineira, Chapada do Guimarães, MT

Ao analisar este parâmetro em campo, nos resultados obtidos observou-se que o $\mathrm{pH}$ do corpo hídrico cresce gradualmente na medida que percorre-se a jusante (Figura 3). Os resultados obtidos nos pontos $\mathrm{P} 1(5,39), \mathrm{P} 2(5,56), \mathrm{P} 3(5,88)$ e $\mathrm{P} 4(6,14)$, tendem à acidez supondo que podem estar diretamente relacionados à formação geológica onde o corpo hídrico nasce, conforme estudo de Salomão et al. (2012). Já as alterações dos valores de pH a partir dos pontos P5 $(7,02)$ e P6 $(7,35)$ supõe-se estar relacionado com a influência de lançamentos de esgotos sanitários evidenciados a jusante do P4, demonstrando um desequilíbrio, porém, P5 e P6 encontram-se dentro dos padrões legais da legislação pertinente. 


\subsection{Turbidez}

A turbidez representa o grau de interferência à passagem da luz através da água. Quando de origem natural, pode estar associado a partículas de rocha, argila e silte, algas e outros microorganismos, no entanto, quando de origem antropogênica pode estar relacionado a compostos tóxicos e organismos patogênicos (BINOTTO, 2012).

A erosão das margens dos rios em estações chuvosas, que é intensificada pelo mau uso do solo, é um exemplo de fenômeno que resulta em aumento da turbidez. Os esgotos sanitários e diversos efluentes industriais também provocam elevações na turbidez das águas. Um exemplo típico deste fato ocorre em consequência das atividades de mineração, onde os aumentos excessivos de turbidez têm provocado formação de grandes bancos de lodo em rios e alterações no ecossistema aquático (CETESB, 2009).

\section{Turbidez}

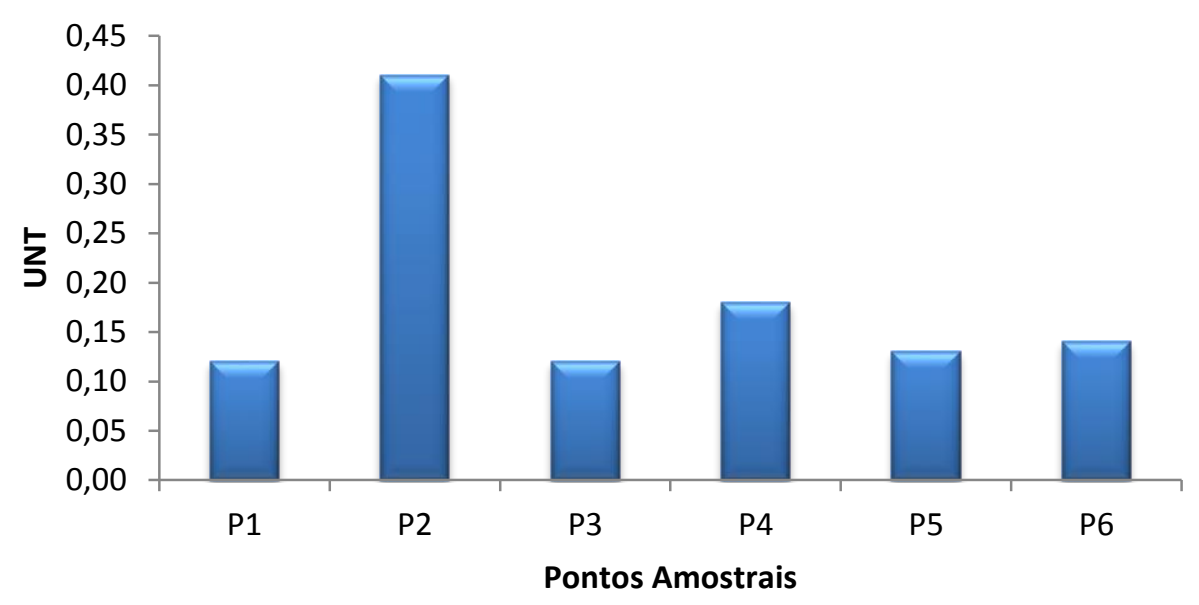

Figura 4 - Variação da turbidez da água ao longo do Córrego Quineira, Chapada do Guimarães, MT

De acordo com os resultados (Figura 4), pode-se afirmar que os valores obtidos encontramse em baixos teores. Nota-se uma considerável alteração no ponto amostral P2 comparando com os demais pontos, provavelmente relacionado a uma movimentação da água e do sedimento no ponto amostral a montante no momento de coleta.

\subsection{Condutividade Elétrica}

Em regiões onde há uma floresta ripária bem conservada a condutividade elétrica que é um fator fundamental na medida da qualidade da água, é muito baixa $\left(<20 \mu \mathrm{S} . \mathrm{cm}^{-1}\right)$. Em regiões com ausência de floresta ripária esta condutividade é muito mais elevada ( $>100 \mu \mathrm{S} . \mathrm{cm}^{-1}$ ) o que evidencia aumento da composição iônica de água, resultado da drenagem superficial (TUNDISI, 2010). 


\section{Condutividade}

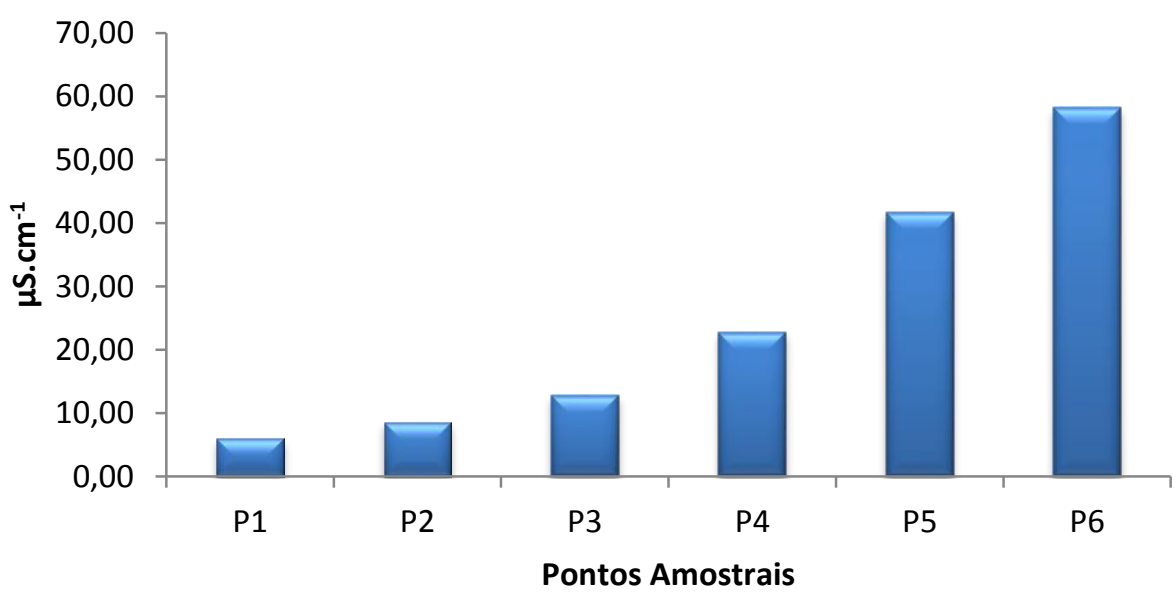

Figura 5 - Variação da condutividade elétrica da água ao longo do Córrego Quineira, Chapada do Guimarães, MT

Os resultados obtidos para condutividade variaram entre 6,02 e 58,20 $\mu \mathrm{S} . \mathrm{cm}^{-1}$ (Figura 5). Tais resultados indicam pequena variação, que se deve provavelmente tipo de afloramentos de rocha encontrados no leito e calha do córrego Quineira, justificando o aumento da condutividade a jusante, bem como a o lançamento de esgoto sanitário a jusante de P4, porém, nota-se a existência de integridade da vegetação ripária corroborando o observado por Tundisi (2010).

\subsection{Coliformes Totais}

Os coliformes totais são um grupo de bactérias que contém bacilos gram-negativos, aeróbios ou anaeróbios facultativos, não formadores de esporos, oxidase-negativa, capazes de crescer na presença de sais biliares ou outros compostos ativos de superfície, com propriedades similares de inibição de crescimento, e que fermentam a lactose com produção de ácidos, aldeídos e gás a 35드 em 24-48 horas (BETTEGA, 2006).

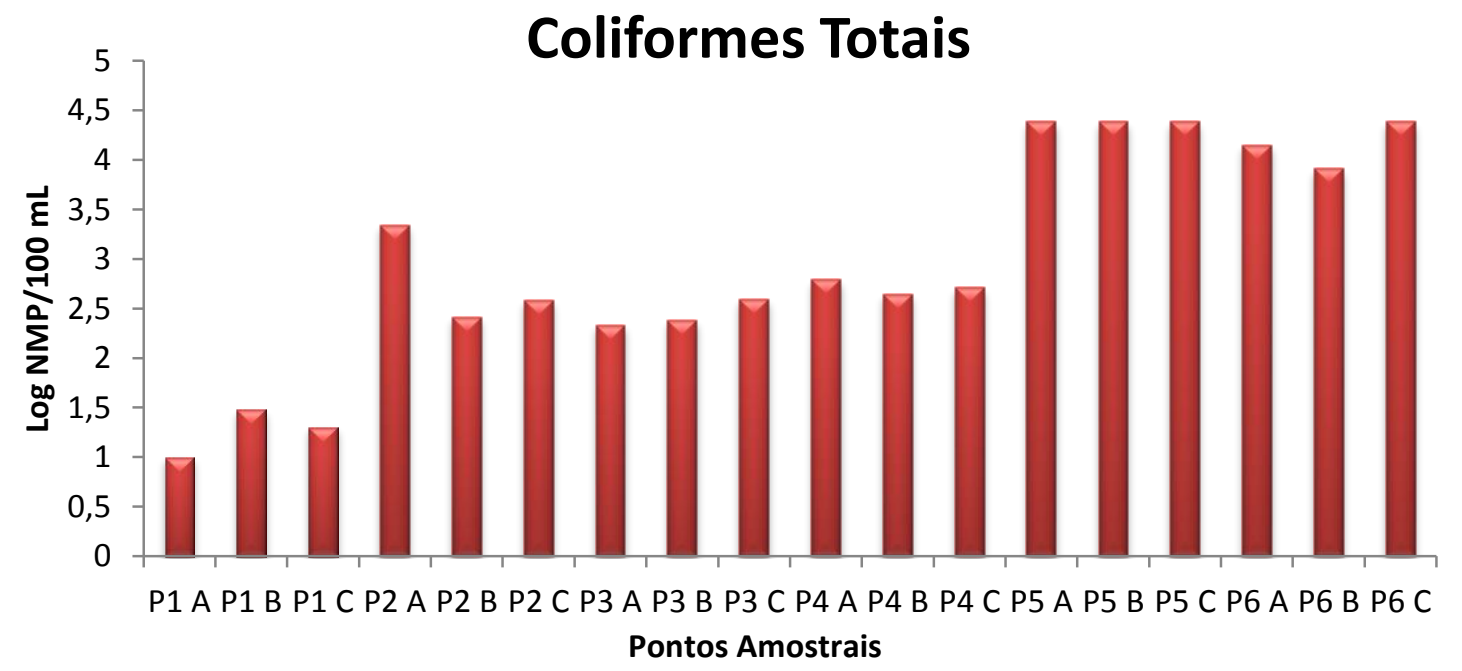

Figura 6 - Variação da concentração de coliformes totais nas amostras de água coletadas em triplicata ao longo do Córrego Quineira, Chapada do Guimarães, MT 
Observa-se na Figura 6 que há presença de coliformes totais em todo gradiente longitudinal do córrego do Quineira. De acordo com a legislação ANVISA (2005) para águas naturais, o ponto de complexo de nascentes encontra-se fora dos padrões estabelecidos. Com relação à balneabilidade que ocorre no ponto amostral 4. Nos pontos amostrais 5 e 6 , ocorreu expressivo aumento, provavelmente devido ao lançamento de esgoto sanitário após P4, ultrapassando o valor de $1000 \mathrm{NMP} / 100 \mathrm{~mL}$. Vale salientar que não há padrão legal para esta variável microbiológica nas resoluções do CONAMA 357/05 e 274/00.

\subsection{Escherichia coli}

Dentre o grupo de bactérias coliformes que estão presentes nas fezes, segundo Silveira et al. (2009), 95\% são representadas pela Escherichia coli (E. coli), sendo a principal bactéria indicadora de contaminação fecal através de fezes cuja origem é exclusivamente de humanos ou animais de sangue quente indicando contaminação recente.

A pesquisa de $E$. coli em termos de saúde pública é de grande importância como parâmetro indicador de possibilidade de presença de microrganismos patogênicos podendo ser responsáveis por doenças de veiculação hídrica como a febre tifoide, cólera, e etc. Em cursos d'água, este grupo de bactérias indicam poluição por lançamento de esgoto sanitários in natura o que caracteriza a ausência de saneamento básico adequado.

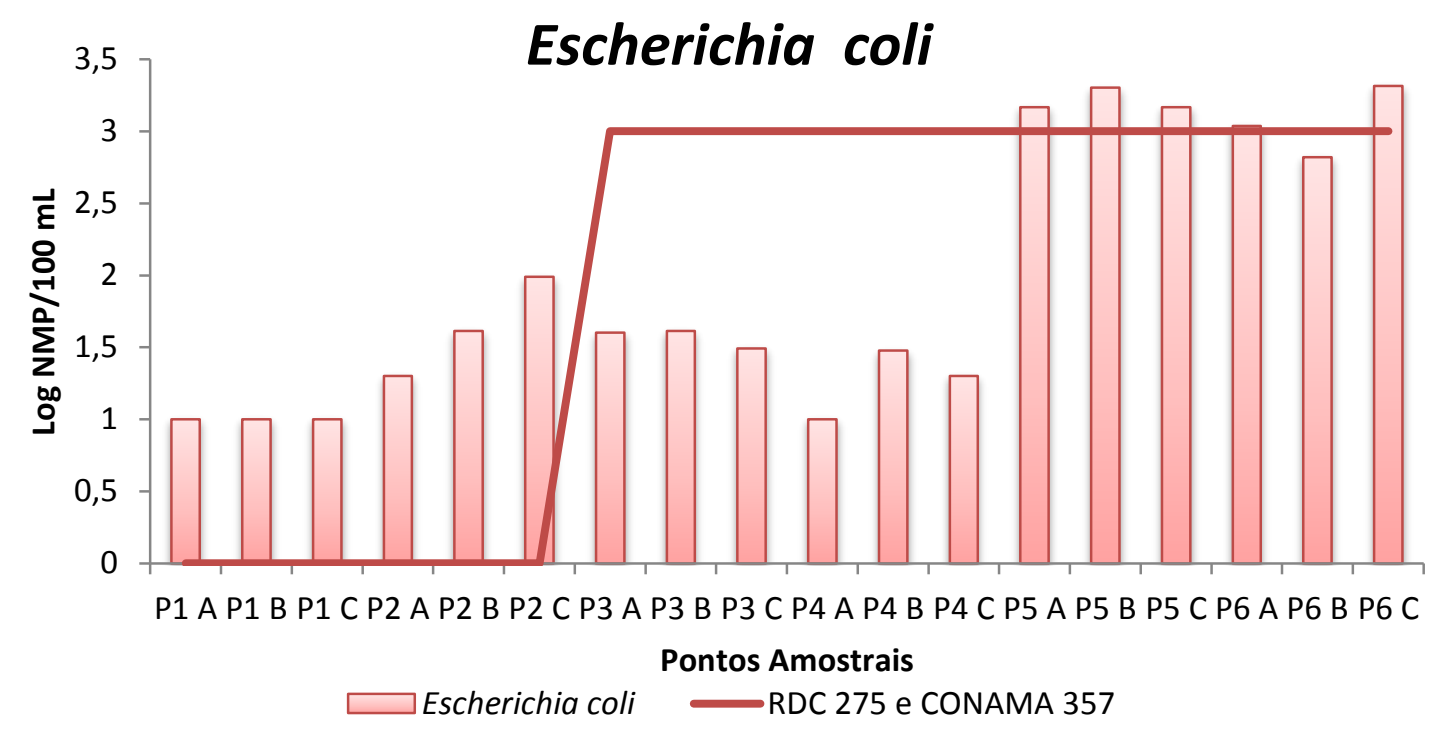

Figura 7 - Variação da concentração de E. coli nas amostras de água coletadas em triplicata ao longo do Córrego Quineira, Chapada do Guimarães, MT

Apesar da ocorrência de $E$. coli no ponto amostral do complexo de nascentes (P1 e P2), em desacordo com a legislação ANVISA (2005), nota-se que os resultados obtidos foram pequenos o que indica presença de animais silvestres para a dessedentação e também de avifauna, indicando ainda, que o ponto 1 encontra-se relativamente preservada (Figura 7). Os pontos P3 e P4, apresentaram resultados de $500 \mathrm{NMP} / 100 \mathrm{~mL}$ em média, não caracterizando um resultado expressivo. No entanto, para os pontos P5 e P6, os valores se elevam significantemente obtendo resultados superiores a $20.000 \mathrm{NMP} / 100 \mathrm{~mL}$, indicando contaminação por lançamento de esgoto 
sanitário a jusante de P4, onde foi verificada in loco a ocorrência de ligações clandestinas em galerias de águas pluviais. Os resultados para P5 e P6 encontram-se em desacordo com a legislação do CONAMA (2000; 2005), podendo ser considerada imprópria para contato primário.

\section{CONCLUSÃO E RECOMENDAÇÕES}

Após interpretações dos resultados físicos, químicos e microbiológicos, é possível afirmar que tanto o complexo de nascentes bem como sua confluência encontram-se relativamente conservados. Muito embora haja ocorrência de uso e ocupação do solo em todo o entorno da microbacia bem como nas partes de cabeceira, não existem fortes indícios de degradação ambiental destes pontos.

Apesar dos resultados das análises bacteriológicas apresentarem-se fora dos padrões estabelecidos pela legislação vigente nos pontos P1 e P2, não se pode afirmar que a antropização no entorno da microbacia esteja afetando a qualidade da água destes pontos, tendo em vista os dados estarem apontando para as condições naturais, o que pode ser confirmado pela ausência de chuvas que faz a conexão do entorno com os corpos d'água através do escoamento superficial, ocasionando o aporte de nutrientes, resíduos e matérias orgânicas.

Percebe-se que no decorrer do gradiente longitudinal do córrego do Quineira até o ponto amostral P4, ocorrem diversas alterações dos parâmetros avaliados, devido principalmente às características ali encontradas como tipo de solo, alteração de substrato, bem como fatores como represamento de um dos pontos amostrais para captação, tratamento e posterior distribuição para abastecimento público. Porém, a jusante do ponto amostral P4, foi constatado in loco, lançamento de esgoto sanitário nas duas margens do córrego, através de ligações clandestinas nas galerias de águas pluviais, validando os resultados microbiológicos e, indicando que as alterações ocorridas nos pontos P5 e P6 estão fortemente ligadas às ações antropogênicas na microbacia objeto deste estudo.

Neste sentido, tornam-se necessárias medidas de controle ambiental e de caráter preventivos quais sejam:

- Fiscalizar o acesso às nascentes, com permissão apenas para estudos e pesquisas, tendo em vista se tratar de um Parque Estadual;

- Fiscalizar o uso do recurso hídrico da microbacia e buscar novas alternativas para o abastecimento público;

- Realizar levantamento completo de ligações clandestinas de esgoto na rede de águas pluviais e adequar o sistema de esgotamento sanitário e drenagem urbana do município.

\section{AGRADECIMENTOS}

Agradecemos aos colegas Mestrandos em Recursos Hídricos Turma de 2013 que apoiaram de alguma forma na coleta de amostras, bem como em algumas análises realizadas. 
O Departamento de Engenharia Sanitária e Ambiental da Universidade Federal de Mato Grosso pela liberação do uso dos Laboratórios de Físico-Química e Microbiologia, bem como aos técnicos de laboratórios pelas orientações nas análises.

A CAPES/CNPq, pela concessão de bolsas de Mestrado, que viabiliza o estudo e dedicação integral.

\section{REFERÊNCIAS}

1. APHA - American Public Health Association /AWWA - American Water Works Association \& WPCF/Water Pollution Control Federation. Standard Methods. Washington: Ed. APHA, 2012. 22 a ed.

2. BetTegA, Janine Maria Pereira Ramos et al. Métodos analíticos no controle microbiológico de água para consumo humano. Cienc. agrotec. [online]. 2006, vol.30, n.5, pp.950-954. ISSN 1413-7054.

3. BINOTTO, D. Proposta de enquadramento para a Bacia Hidrográfica do Arroio Jucutinga, Município de Ivorá-RS. Santa Maria - RS, 2012. 133 f. Dissertação (Mestrado) - Programa de Pós-Graduação em Engenharia Civil. Universidade Federal de Santa Maria, 2012.

4. BRASIL. Conselho Nacional do Meio Ambiente. Resolução CONAMA no 274/2000. Define os critérios de balneabilidade em águas brasileiras.

5. _ Conselho Nacional do Meio Ambiente. Resolução CONAMA no 357/2005. Dispõe sobre a classificação dos corpos de água e diretrizes ambientais para o seu enquadramento.

Conselho Nacional do Meio Ambiente. Resolução CONAMA no 001/1986. Dispõe sobre critérios básicos e diretrizes gerais para a avaliação de impacto ambiental.

7. __ Resolução ANVISA no. 275 de 22 de Setembro de 2005. Regulamento técnico de características microbiológicas para água mineral natural e água natural.

8. CETESB - COMPANHIA AMBIENTAL DO ESTADO DE SÃO PAULO. Guia nacional de coleta de amostras: água, sedimento, comunidades aquáticas e efluentes líquidos. Organizadores: Carlos Jesus Brandão...(et al.) - São Paulo: CETESB; Brasília: ANA, 2011.

9. COMPANHIA AMBIENTAL DO ESTADO DE SÃO PAULO. Significado ambiental e sanitário das variáveis de qualidade das águas e dos sedimentos e metodologias analíticas e de amostragem. São Paulo: CETESB; 2009.

10. ESTEVES, F. D. Fundamentos de Limnologia. 3ạEd. Rio de Janeiro: Interciência, 2011. 826 p.

11. FIGUEIREDO, D.M. Limnologia e qualidade das águas superficiais das sub-bacias alta e média. In: FIGUEIREDO, D.M. \& SALOMÃO, F.X.T. Bacia do rio Cuiabá: uma abordagem socioambiental. Cuiabá: Entrelinhas: EdUFMT, 2009. 41-45 p.

12. LIMA, Zoraidy Marques de. Qualidade da água do rio Bento Gomes (Pantanal de Poconé, MT) com Ênfase em Microbiologia Ambiental. Dissertação de Mestrado em Ecologia e Conservação da Biodiversidade pela Universidade Federal de Mato Grosso. Cuiabá-MT. 1998. 107 p.

13. REBOUÇAS. , A. C. Água Doce no Mundo e no Brasil. In: REBOUÇAS. , A. C. BRAGA. , B \& TUNDISI. , J. G. Águas Doces no Brasil: Capital Ecológico, Uso e Conservação. 3ạ Ed. São Paulo: Escrituras, 2006. 01-35 p. 
14. SALOMÃO, F. X. T.; MADRUGA, E. L.; MIGLIORINI, R. B. Carta geotécnica do perímetro urbano da Chapada dos Guimarães: subsídios ao plano diretor. Revista do Instituto de Geociências da USP, Série científica, São Paulo, v. 12, n. 1, p. 15, Abril 2012.

15. SILVEIRA, A. et al. Desafios do Saneamento Ambiental. Curso de Capacitação. Cuiabá: Gráfica Print Indústria e Editora Ltda, 2009. 102 p.

16. TUCCI, C.E.M. Gestão integrada das águas urbanas. Revista de Gestão de Água da América Latina, vol. 5. no 2, p. 71-81, jul./dez. 2008.

17. TUNDISI, J.G. \& MATSUMURA-TUNDISI, T.M. Impactos potenciais das alterações do Código Florestal nos recursos hídricos. Biota Neotrop., vol. 10. № 4, p.67-76, Novembro 2010.

18. VON SPERLING. M. Introdução à qualidade das águas e ao tratamento de esgotos. 2ำ Ed. Belo Horizonte: Departamento de Engenharia Sanitária - Ambiental. UFMG. 1996. 243 p. 